\title{
Chromosome 4q Deletion Syndrome: Narrowing the Cardiovascular Critical Region to 4q32.2-q34.3
}

\author{
Wenbo Xu, ${ }^{1}$ Ayesha Ahmad, ${ }^{1 *}$ Susan Dagenais, ${ }^{3}$ Ramaswamy K. Iyer, ${ }^{1}$ and Jeffrey W. Innis ${ }^{1,2}$ \\ ${ }^{1}$ Department of Pediatrics, The University of Michigan Medical School, Ann Arbor, Michigan \\ ${ }^{2}$ Department of Human Genetics, The University of Michigan Medical School, Ann Arbor, Michigan \\ ${ }^{3}$ DNA Sequencing Core Laboratory, The University of Michigan Medical School, Ann Arbor, Michigan
}

Received 4 March 2011; Accepted 2 November 2011

The $4 \mathrm{q}$ deletion syndrome is a rare chromosome deletion syndrome with a wide range of clinical phenotypes. There is limited clinical phenotype and molecular correlation for congenital heart defects (CHDs) reported so far for this region primarily because many cases are large deletions, often terminal, and because high-resolution array has not been reported in the evaluation of this group of patients. CHDs are reported in about $60 \%$ of patients with $4 \mathrm{q}$ deletion syndrome, occurring in the presence or absence of $d H A N D$ deletion, implying the existence of additional genes in 4q whose dosage influences cardiac development. We report an 8-month-old patient with a large mid-muscular to outlet ventricular septal defect (VSD), moderate-sized secundum-type atrial septal defect (ASD), thickened, dysplastic pulmonary valve with mild stenosis and moderate pulmonic regurgitation, and patent ductus arteriosus (PDA). Illumina CytoSNP array analysis disclosed a de novo, heterozygous, interstitial deletion of $11.6 \mathrm{Mb}$ of genomic material from the long arm of chromosome 4, at 4q32.3-q34.3 (Chr4:167236114-178816031; hg18). The deleted region affects 37 RefSeq genes (hg18), including two provisional microRNA stemloops. Three genes in this region, namely TLL1 (Tolloidlike-1), HPGD (15-hydroxyprostaglandin dehydrogenase), and HAND2 (Heart and neural crest derivatives-expressed protein 2), are known to be involved in cardiac morphogenesis. This report narrows the critical region responsible for CHDs seen in $4 \mathrm{q}$ deletion syndrome. $\odot 2012$ Wiley Periodicals, Inc.

Key words: 4q deletion syndrome; ventricular septal defect (VSD); atrial septal defect (ASD)

\section{INTRODUCTION}

Since its first description [Ockey et al., 1967], the clinical phenotype of 4q deletion syndrome has been delineated by several groups [Mitchell et al., 1981; Yu et al., 1981; Lin et al., 1988; Strehle and Bantock, 2003], with an incidence estimated at 1/100,000 and overall mortality of $28 \%$ [Strehle and Bantock, 2003]. The most common anomalies observed in patients include mental deficiency (92\%); postnatal onset of growth deficiency (83\%); craniofacial anomalies including broad nasal bridge (94\%), rotated ears (56\%),
How to Cite this Article:

Xu W, Ahmad A, Dagenais S, Iyer RK, Innis

JW. 2012. Chromosome 4q deletion

syndrome: Narrowing the cardiovascular critical region to $4 \mathrm{q} 32.2-\mathrm{q} 34.3$.

Am J Med Genet Part A 158A:635-640.

cleft palate (94\%), and micrognathia (94\%); congenital heart defects (CHDs) (50\%) including ventricular septal defect (VSD), patent ductus arteriosus (PDA), peripheral pulmonic stenosis, aortic stenosis, atrial septal defect (ASD), tetralogy of Fallot, aortic coarctation, tricuspid atresia; and digital anomalies (especially of the fifth finger) (50-88\%). Gastrointestinal and renal anomalies are less common [Mitchell et al., 1981; Yu et al., 1981; Lin et al., 1988; Strehle and Bantock, 2003].

The severity of malformations varies widely and depends on the chromosomal position and deletion size. Loss of 4q31-q34 region is responsible for most of the clinical phenotype [Giuffrè et al., 2004], and Keeling et al. [2001] proposed that the 4q33 region is the critical region for $4 \mathrm{q}$ deletion syndrome. However, no reports have used contemporary high-resolution array CGH that would promote assembly of an accurate genotype/phenotype correlation for the CHDs.

We report an 8-month-old male patient with CHDs, growth delay, and minor skeletal anomalies with a loss of $11.6 \mathrm{Mb}$ of genomic material from the long arm of chromosome 4, at 4q32.3-q34.3 (Chr4: 167236114-178816031; hg18). This region contains 37 RefSeq genes including several with potential heart and/ or vascular relevance: TLL1 (Tolloid-like-1), HPGD (15-hydroxy-

Wenbo Xu and Ayesha Ahmad equally contributed to this work. ${ }^{\star}$ Correspondence to:

Ayesha Ahmad, MD, Division of Pediatric Genetics, Department of Pediatrics and Communicable Diseases, University of Michigan Medical Center, D5240 Medical Professional Building, 1500 E. Medical Center Drive Ann Arbor, MI 48109-0718. E-mail: ayeshaah@umich.edu Published online 2 February 2012 in Wiley Online Library (wileyonlinelibrary.com).

DOI 10.1002/ajmg.a.34425 
prostaglandin dehydrogenase), and HAND2 (Heart and neural crest derivatives-expressed protein 2). Together with other reports, our description narrows the critical region responsible for the CHDs in 4q deletion syndrome to Chr4:167236114-178816031.

\section{CLINICAL REPORT}

The proband was born at a gestational age of 35 2/7 weeks by cesarean to a healthy 24-year-old gravida 5, para 2-3 mother. A prenatal diagnosis of a CHD was made. His birth weight was $3.16 \mathrm{~kg}$ (78th centile), length was $50 \mathrm{~cm}$ (85th centile), and head circumference (OFC) was $34 \mathrm{~cm}$ (85th centile). The baby was cyanotic at delivery, intubated for poor respiratory effort at birth, and received one dose of surfactant. Initial echocardiogram showed large midmuscular to outlet VSD with bidirectional shunt, moderate-sized secundum-type ASD, thickened, dysplastic pulmonary valve with mild stenosis, and moderate pulmonic regurgitation. He underwent PDA ligation and VSD repair at age 3 months. His postnatal course was complicated by milk protein intolerance, failure to thrive, and gastroesophageal reflux. There was mild developmental delay at age 7 months, since he was not sitting independently, but was otherwise age-appropriate. On physical exam at 7 months, his weight was $5.9 \mathrm{~kg}$ (less than 5 th centile), length was $60 \mathrm{~cm}$ (less than 5 th centile), and OFC was $43.6 \mathrm{~cm}$ (23rd centile). He had posteriorly rotated ears with simplified helices, pointed on the right. No other significant dysmorphic facial features were noted (parents declined facial photographs). There was overlap of toes $4-5$ on both feet. Nails of fifth fingers were normal bilaterally (Fig. 1). Physical examination was otherwise unremarkable. Renal ultrasound noted bilateral extrarenal pelvis.

\section{METHODS}

\section{Postnatal Array CGH Analysis}

Array CGH analyses were performed using the custom-designed EMArray Cyto6000 array platform [Baldwin et al., 2008], a sexmismatched, pooled, normal DNA control for comparison, and standard protocols implemented in the Michigan Medical Genetics Laboratory at the University of Michigan.

\section{Array CGH Data Analysis}

The array data were imported into, analyzed and plotted by the Agilent CGH Analytics version 3.5 or DNA analytics version 4.0.81 software (Agilent Technologies, Santa Clara, CA). For reporting of copy number changes detected by CMA, nucleotides are numbered according to Genome Build UCSC hg18 (March 2006) assembly, and results are reported as per the International System for Human Cytogenetic Nomenclature (ISCN) 2009 recommendations.

\section{Illumina Array}

To refine the deletion endpoints, an Illumina Human CytoSNP12v2.1 BeadChip Kit (Illumina, INC., San Diego, CA) with average probe spacing of $10 \mathrm{~kb}$, was used for the analysis. DNA was quantified with the Quant-iT ${ }^{\mathrm{TM}}$ PicoGreen ${ }^{\circledR}$ dsDNA Kit (Invitrogen Corporation, Carlsbad, CA). 200 ng DNA was utilized

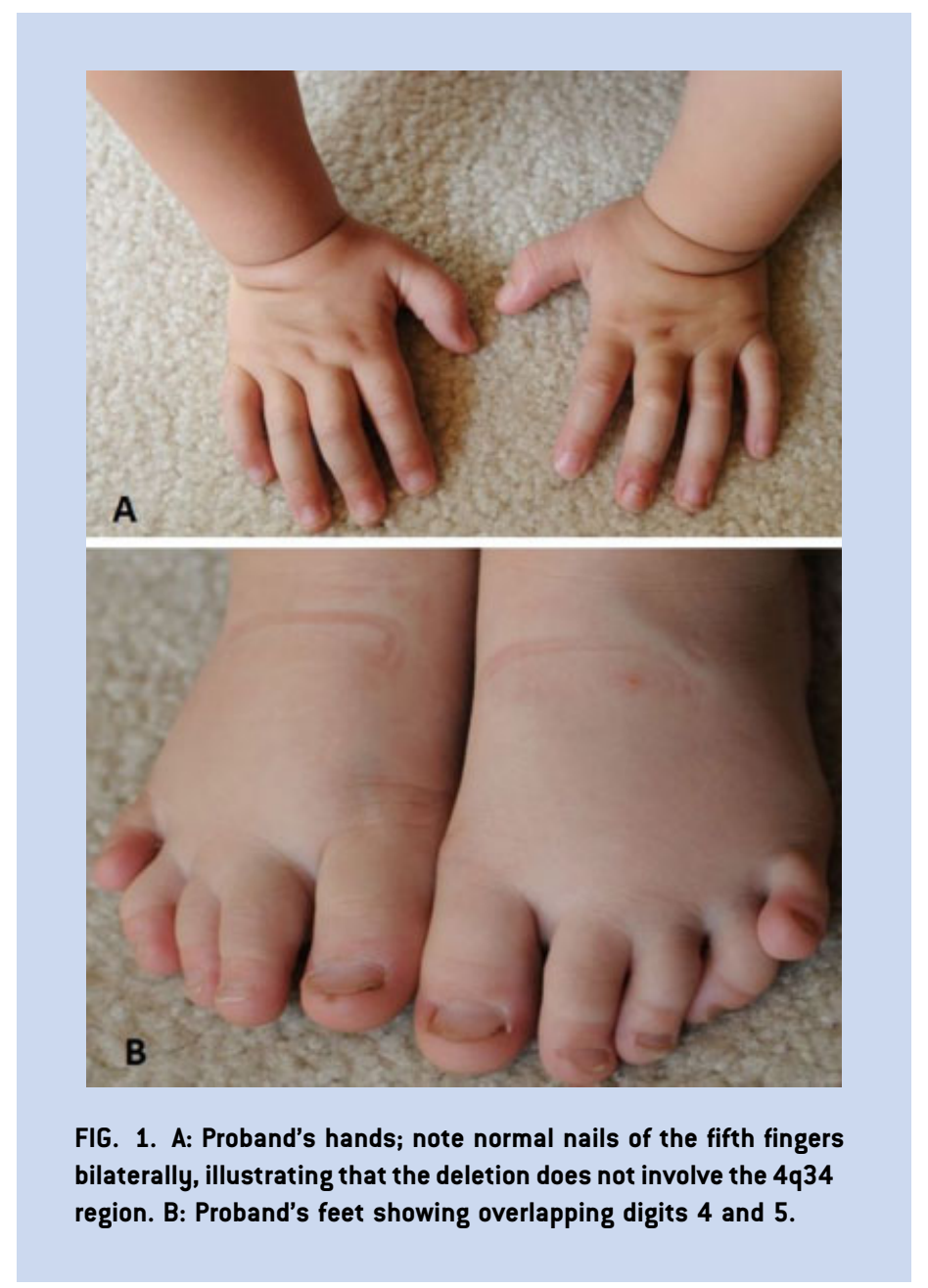

in an Illumina Infinium ${ }^{\circledR}$ HD Ultra Assay according to the manufacturer's instructions. HumanCytoSNP BeadChips were scanned with an Illumina iScan Reader. Image data were analyzed using the Illumina GenomeStudio (v2010.2) Genotyping Analysis Module (v1.7.4) Software. SNP cluster positions were defined based on the HumanCytoSNP cluster file provided by Illumina, Inc. Genome positions were determined using Build 36.1 (hg18).

\section{Fluorescence In Situ Hybridization (FISH)}

Metaphase FISH analysis was performed at Emory Genetics Labs on samples from the proband and the biological parents of the proband, using a custom-labeled Bacterial Artificial Chromosome (BAC) probe, RP11-119J20, located within the region of interest at 4q. A 4q subtelomere-specific probe (Abbott Molecular Inc., Des Plaines, IL) was used as a control.

\section{RESULTS}

Array CGH analysis using the EmArray detected a male chromosome profile, with a $11.6 \mathrm{Mb}$ loss of genomic material from the long arm of chromosome 4, at 4q32.3-q34.3. To further define the deletion breakpoints, we used higher density Illumina CytoSNP analysis and this revealed heterozygous loss for 
TABLE I. Phenotype Comparison Between Our Case and Published Cases With 4q Deletion Syndrome [Adapted From Strehle and Bantock, 2003]

\section{Characteristic}

Male/female ratio

Abnormal parental chromosomes

Prematurity

Developmental delay

Growth failure

Mortality

Dysmorphic craniofacial features

Pierre-robin sequence/cleft lip and palate

Central nervous system

Ocular system

Hearing

Digital anomaly

Muscular System

Cardiovascular system

Respiratory tract

Dentition

Gastrointestinal tract

Hepatobiliary system and pancreas

Lymphatic system and spleen

Endocrine system

Renal and urinary tract

Genitalia

Skin/hair

$\begin{gathered}\text { Percentage } \\ 0.91\end{gathered}$
$14 \%(13 / 90)$
$14 \%(12 / 85)$
$94 \%(77 / 82)$
$60 \%(56 / 94)$
$28 \%(28 / 101)$
$99 \%(100 / 101)$
$37 \%(37 / 101)$
$34 \%(34 / 101)$
$44 \%(44 / 101)$
$37 \%(16 / 43)$
$88 \%(89 / 101)$
$45 \%(45 / 101)$
$50 \%(50 / 101)$

$32 \%(32 / 101)$

$18 \%(18 / 101)$

$40 \%(40 / 101)$

$17 \%(17 / 101)$

$8 \%(8 / 101)$

$6 \%(6 / 101)$

$19 \%(19 / 101)$

$28 \%(28 / 101)$

$43 \%(43 / 101)$

$$
\begin{gathered}
\text { This report } \\
\text { Male } \\
- \\
+, 35 \text { wks GA } \\
+, \text { Mild } \\
+ \text {, Failure to thrive } \\
- \\
+
\end{gathered}
$$

No known abn

No known abn

$-$

$-$

$-$

$+$

VSD muscular-outlet;

ASD secundum;

Pulmonic stenosis

No known abn

No known abn

$$
+ \text {, GERD }
$$

No known abn

No known abn

No known abn

+ , Extrarenal pelvis

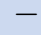

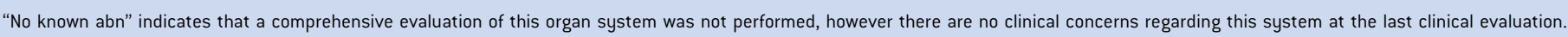
- , no observed clinical problem; + , feature is present.

ASD, atrial septal defect; GA, gestational age; GERD, gastrointestinal reflux disease; VSD, ventricular septal defect.

Chr4:167236114-178816031. The minimal aberrant region contains 37 RefSeq genes (Table I), including TLL1 (; NM_012464.3), HPGD (NM_000860.3) and HAND2 (also known as dHAND; NM_021973.2). To confirm the results as well as to clarify the origin of this microdeletion, we performed FISH analysis on samples from the patient and both parents. FISH utilized BAC probe RP11-119J20 and detected an interstitial deletion in the proband, consistent with the array results (see Fig. 2). A 4q subtelomere-specific probe (Abbott Molecular Inc) was used as a control and it showed a normal hybridization pattern. The 4q deletion is presumed to be de novo since it was not detected in either of the biological parents.

\section{DISCUSSION}

Chromosome 4q deletion syndrome comprises both interstitial and terminal deletions in the long arm of chromosome 4. Both the reported size and region deleted in $4 \mathrm{q}$ deletion syndrome vary greatly among patients, so does the scope of clinical malformations. There are fewer than 200 cases with $4 \mathrm{q}$ deletion reported in the literature and ours is the first to use high-resolution array to define the molecular deletion boundaries in relation to the phenotype.

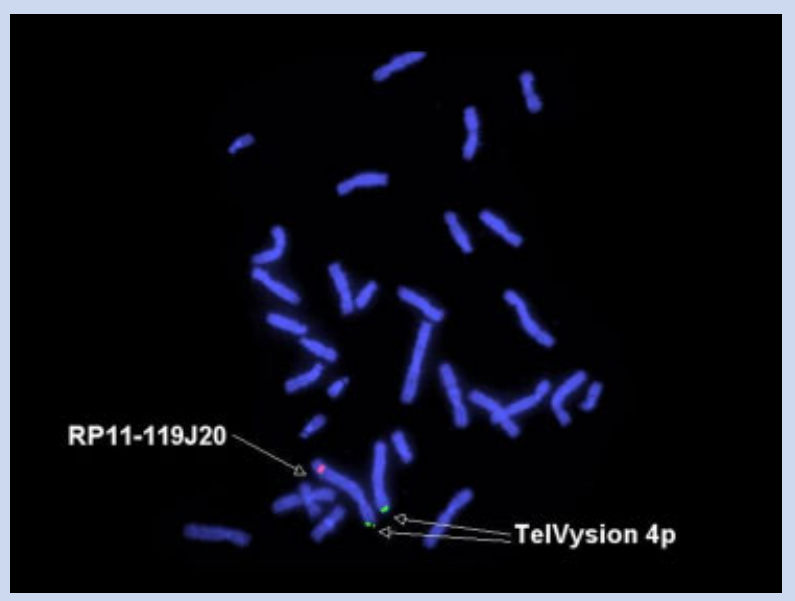

FIG. 2. FISH results of the proband. Bacterial Artificial Chromosome (BAC) probe (RP11-119J20) located within the region of interest (red) detects a $4 q 32.3-34.3$ deletion on one homolog of chromosome 4. A 4q subtelomere-specific probe (Abbott Molecular Inc.) used as a control (green) showed a normal hybridization pattern. 
We compared the clinical findings in our patient with the summary of the clinical characteristics in 101 patients with $4 \mathrm{q}$ deletion syndrome [Strehle and Bantock, 2003] (Table I). The sole major malformation in our patient included the CHDs consisting of a large mid-muscular to outlet VSD, ASD secundum, thickened, and dysplastic pulmonary valve with mild stenosis. Minor anomalies consisted of posteriorly rotated, simplified helices and overlapping of toes 4-5. However, he had small stature and mild developmental delay.

It has been suggested that the $4 \mathrm{q} 32.3-\mathrm{q} 34.3$ region plays a role in cardiac development. One study of five patients reported three patients with terminal deletions involving the dHAND (HAND2) gene, and only two of these individuals had CHD. One other patient with a terminal deletion had an ASD, but $d H A N D$ was not deleted [Huang et al., 2002]. Another study described BAC array compa- rative genomic hybridization (CGH) evaluation of a patient with mild aortic stenosis and dysplasia of the pulmonary valve showing a de novo $4 \mathrm{q}$ terminal deletion of $18.9-22.9 \mathrm{Mb}$ [Kitxiou-Tzeli et al., 2008]. Kaalund et al. [2008] also reported a boy with a VSD who had a $21 \mathrm{Mb}$ interstitial deletion of $4 \mathrm{q}$ (roughly delineated to position $160,717,000-181,668,000)$ using a BAC array. However, none of those reports accurately identified the deletion breakpoints so it is impossible to develop clinical correlations with regard to CHDs.

To evaluate the known contribution of genes in the deleted region to clinical phenotype as well as the potential impact of haploinsufficiency to disease or risk, we examined the deleted chromosomal region in our patient for genes and large copy number variants (CNVs). There are 37 documented RefSeq genes (hg18) (Table II) in the deleted region. There are many small CNVs of a few thousand base pairs, but only one reaching $425 \mathrm{~kb}$. CNVs

TABLE II. 37 RefSeq Genes in the 4q32.3-34.3 Deleted Region of the Proband ${ }^{a}$

\begin{tabular}{|c|c|}
\hline Gene & Description \\
\hline TLL1 & Metalloprotease \\
\hline SPOCK3 & Proteoglycans \\
\hline ANXA10 & $\mathrm{Ca}^{2+}$-dependent phospholipid-binding protein \\
\hline$D D \times 60$ & DEAD (Asp-Glu-Ala-Asp) box polypeptide 60 \\
\hline$D D \times 60 L$ & DEAD box polypeptide 60 -like \\
\hline PALLD & Actin-containing microfilaments \\
\hline CBR4 & Carbonyl reductase 4 \\
\hline SH3RF1 & SH3 domain containing ring finger 1 \\
\hline NEK1 & Never in mitosis gene A-related kinase 1 \\
\hline CLCN3 & Chloride channel 3 \\
\hline C4orf27 & Chromosome 4 open reading frame 27 \\
\hline MFAP3L & Microfibrillar-associated protein 3-like \\
\hline$A A D A T$ & $\alpha$-aminoadipate amino transferase \\
\hline HSP9OAA6P & Heat shock protein $90 \mathrm{kDa}$ alpha \\
\hline GALNTLG & GalNac Transferase-like 6 \\
\hline GALNTT & GalNac Transferase ? \\
\hline HMGB2 & High mobility group protein 2 \\
\hline SAP3O & SIN3-associated polypeptide, 30KD \\
\hline SCRG1 & Scrapie-responsive gene 1 \\
\hline HAND2 & Basic helix-loop-helix transcription factor \\
\hline NBLA00301 & Nbla00301 (non-coding RNA) \\
\hline MORF4 & Mortality factor 4 \\
\hline FBX08 & F-box only protein 8 \\
\hline$K I A A 1>12$ & HBV PreS1-transactivated protein 3 \\
\hline MIR4276 & microRNA 4276 \\
\hline HPGD & 15-@hydroxyprostaglandin dehydrogenase \\
\hline GLRA3 & Glycine receptor, alpha- 3 subunit \\
\hline ADAM29 & A disintegrin and metalloproteinase domain 29 \\
\hline GPMGA & Neuronal membrane glycoprotein M6A \\
\hline MIR1267 & microRNA $126 ?$ \\
\hline WDR17 & WD repeat-containing protein 17 \\
\hline SPATA4 & Spermatogenesis-associated protein 4 \\
\hline ASB5 & Ankyrin repeat and SOCS box containing 5 \\
\hline SPCS3 & Signal peptidase complex subunit 3 homolog \\
\hline VEGFC & Vascular endothelial growth factor C \\
\hline NEIL3 & Endonuclease VIII-like 3 \\
\hline$A G A$ & Aspartylglucosaminidase \\
\hline
\end{tabular}

Chromosomal location $4 q 32.3$

$4 q 32.3$

$4 q 32.3$

$4 q 32.3$

$4 q 32.3$

$4 q 32.3$

$4 \mathrm{q} 32.3$

$4 q 32.3-4 q 33$

$4 q 33$

$4 q 33$

$4 q 33$

$4 q 33$

$4 q 33$

$4 q 33$

$4 q 34.1$

$4 q 34.1$

$4 q 34.1$

$4 q 34.1$

$4 q 34.1$

$4 q 34.1$

$4 q 34.1$

$4 q 34.1$

$4 q 34.1$

$4 q 34.1$

$4 q 34.1$

$4 q 34.1$

$4 q 34.1$

$4 q 34.1$

$4 q 34.2$

$4 q 34.2$

$4 q 34.2$

$4 q 34.2$

$4 \mathrm{q} 34.2$

$4 \mathrm{q} 34.2$

$4 q 34.3$

$4 q 34.3$

$4 q 34.3$ 
are discussed below in the context of specific CHD candidate genes. Several genes in this region possess functions that may correlate with aspects of the patient's clinical, in particular cardiac, phenotype. TLL1, HPGD, and HAND2 are involved in cardiovascular development and/or pathology as we summarize below.

The TLL1 gene encodes an astacin-like metalloprotease that shares structural similarity to the morphogenetically important proteases bone morphogenetic protein-1 (BMP1; MIM:112264) and Drosophila Tolloid (TLD). Homozygous (Tll1-/-) is embryonic lethal in mice from cardiac failure and a constellation of CHDs at midgestation. The major pathological features included incomplete formation of the muscular interventricular septum and an abnormal and novel positioning of the heart and aorta. TLL1 plays multiple roles in the formation of the interventricular septum and other parts of the heart [Clark et al., 1999]. Heterozygous ( $T l l 1+/-$ ) mutant mice appear grossly normal, survive to adulthood, and are fertile [Clark et al., 1999]. We are not aware of a pathological CHD in the Tll1+/- mouse. In humans, in 19 unrelated patients with ASD (MIM\# 613087) with or without other CHDs, three heterozygous missense mutations were identified in TLL1 in three patients [Stanczak et al., 2009]. Two mutations (Met182Leu, and Ala238Val) were identified in two patients with ASD only, and another (Leu627Val), was detected in a patient with ASD with an interatrial septum aneurysm [Stanczak et al., 2009]. These data support the hypothesis that heterozygous deletion of TLL1 may contribute to the development of ASD in our patient. We did not sequence the TLL1 gene of the non-deleted chromosome. Examination of the TLL1 gene region in the Database of Genomic Variants (DGV) revealed the presence of five CNVs. One of the CNVs is a $425 \mathrm{~kb}$ deletion (Chr4:167057083-167482075) [Sebat et al., 2004]; the other four CNVs are around or less than $1 \mathrm{~kb}$. The $425 \mathrm{~kb}$ deletion truncates the TLL1 gene in the $5^{\prime}$-UTR and was observed in 1 out of 20 control samples [Sebat et al., 2004]. Examination of the EMArray and Illumina CytoSNP data revealed only heterozygous TLL1 loss in this region.

$H P G D$, (also called $P G D H$ ) is the main enzyme of prostaglandin degradation. By catalyzing the conversion of the 15-hydroxyl group of prostaglandins into a keto group, this ubiquitous enzyme strongly reduces the biologic activity of these molecules. Pgdh $-/-$ mice die between 12 and $48 \mathrm{hr}$ of postnatal life because of PDA leading to congestive heart failure [Coggins et al., 2002]. Treatment with indomethacin rescued the mice. Coggins et al. [2002] concluded that alterations in prostaglandin $\mathrm{E}_{2}\left(\mathrm{PGE}_{2}\right)$ metabolism by PGDH during the perinatal period are essential for permanent closure of the ductus arteriosus. $P G D H$ mutations are also reported to be associated with autosomal recessive primary hypertrophic osteoarthropathy (PHO; MIM:259100). Four of 13 PGDH homozygous deficient (c.175_176delCT/p. L59VfsX8, c.232_241delinsCA/p.V78QfsX11, c. 418G > C/p.A140P) patients had a persistent PDA that may have resulted from increased $\mathrm{PGE}_{2}$ [Uppal et al., 2008]. Though Coggins et al. concluded that alterations in $\mathrm{PGE}_{2}$ metabolism by $\mathrm{PGDH}$ during the perinatal period is essential for the permanent closure of the ductus arteriosus, most patients did not have PDA, suggesting that loss of PGDH activity is not sufficient to cause failure of ductal closure in humans. Supporting this idea, both dominant and recessive inheritance of $\mathrm{PHO}$ have been reported, suggesting a complicated role for $P G D H$ in the course of disease [Uppal et al., 2008]. In our patient, heterozygous deletion of the $P G D H$ gene could contribute to the occurrence of PDA. We did not sequence the $P G D H$ gene of the non-deleted chromosome. Examination of the $P G D H$ gene region in DGV revealed no CNVs.

The HAND2 (MIM \# 602407) gene encodes a basic helixloop-helix transcription factor that, along with the closely related HAND1 protein, plays an essential role in cardiac morphogenesis. Hand2 is particularly important for the formation of the right ventricle and the aortic arch arteries [Srivastava et al., 1997]. Hand2 is expressed in the developing vascular mesenchyme and its derivative, vascular smooth muscle cells. Hand $2^{-/-}$mice die at embryonic day 10.5 from heart failure [Srivastava et al., 1997], and have severe defects of embryonic and yolk sac vascular development by embryonic day 9.5 [Yamagishi et al., 2000]. In a group of 131 patients diagnosed with CHDs of the right ventricle, outflow tract, aortic artery, or cardiac cushion, Shen et al. [2010] found seven HAND2 mutations in 12 patients: Three missense mutations (Pro11Arg, Ser36Asn, and Val83Leu), one synonymous mutation (His14His) and three mutations in the $5^{\prime}$ and $3^{\prime}$ untranslated regions $(241 \mathrm{~A}>\mathrm{G}, 604 \mathrm{C}>\mathrm{T}$, and $3237 \mathrm{~T}>\mathrm{A})$. In patients with terminal $4 \mathrm{q}$ deletions and CHDs, loss of HAND2 is associated with pulmonary valve stenosis or partial anomalous pulmonary venous return, however, some patients do not have CHDs when HAND2 is deleted, and others have CHDs when HAND2 is not deleted [Huang et al., 2002]. Therefore, other genes in the region or elsewhere are likely involved in producing CHDs in these patients. We did not sequence the HAND2 gene of the non-deleted chromosome. Examination of the HAND2 gene region in the DGV revealed no CNVs.

Using high resolution array studies we have narrowed the critical region for CHDs in $4 \mathrm{q}$ deletion syndrome to an $11.6 \mathrm{Mb}$ interval. The contribution of other genes in the deleted region to CHDs is unknown, and it is certainly possible that other genes proximal or distal to this deletion are also critical for heart development. However, based on the clinical phenotype of our patient and knowledge of gene function from human and animal models, it is attractive to speculate that in our patient TLL1 loss of function correlates with ASD; that $P G D H$ loss of function is implicated in the PDA; and that HAND2 loss of function was critical in the CHDs of the right side of the heart. Our patient's CHDs could also result from interactions among the TLL1, PGDH, HAND2 and other genes in this deleted region or downstream targets. Ongoing identification of patients with smaller deletions in this region of chromosome 4 will help to further narrow the critical region for CHDs in $4 \mathrm{q}$ deletion syndrome.

\section{REFERENCES}

Baldwin EL, Lee JY, Blake DM, Bunke BP, Alexander CR, Kogan AL, Ledbetter DH, Martin CL. 2008. Enhanced detection of clinically relevant genomic imbalances using a targeted plus whole genome oligonucleotide microarray. Genet Med 10:415-429.

Clark TG, Conway SJ, Scott IC, Labosky PA, Winnier G, Bundy J, Hogan BLM, Greenspan DS. 1999. The mammalian Tolloid-like 1 gene, Tll1, is necessary for normal septation and positioning of the heart. Development 126:2631-2642. 
Coggins KG, Latour A, Nguyen MS, Audoly L, Coffman TM, Koller BH. 2002. Metabolism of PGE2 by prostaglandin dehydrogenase is essential for remodeling the ductus arteriosus. (Letter) Nature Med 8:91-92.

Giuffrè M, La Placa S, Carta M, Cataliotti A, Marino M, Piccione M, Pusateri F, Meli F, Corsello G. 2004. Hypercalciuria and kidney calcifications in terminal $4 \mathrm{q}$ deletion syndrome. Am J Med Genet Part A 126A:186-190.

Huang T, Lin AE, Cox GF, Golden WL, Feldman GL, Ute M, SchranderStumpel C, Kamisago M, Vermeulen SJT. 2002. Cardiac phenotypes in chromosome 4q- syndrome with and without a deletion of the dHAND gene. Genet Med 4:464-467.

Kaalund SS, Møller RS, Tészás A, Miranda M, Kosztolanyi G, Ullmann R, Tommerup N, Tümer Z. 2008. Investigation of 4q-deletion in two unrelated patients using array CGH. Am J Med Genet Part A 146A: 2431-2434.

Keeling SL, Lee-Jones L, Thompson P. 2001. Interstitial deletion 4q32-34 with ulnar deficiency: $4 \mathrm{q} 33$ may be the critical region in $4 \mathrm{q}$ terminal deletion syndrome. Am J Med Genet 99:94-98.

Kitxiou-Tzeli S, Sismani C, Koumbaris G, Ioannides M, Kanavakis E, Kolialexi A, Mavrou A, Touliatou V, Patsalis PC. 2008. Distal del(4)(q33) syndrome: Detailed clinical presentation and molecular description with array-CGH. Eur J Med Genet 51:61-67.

Lin AE, Garver KL, Diggans G, Clemens M, Wenger SL, Steele MW, Jones MC, Israel J. 1988. Interstitial and terminal deletions of the long arm of chromosome 4: Further delineation of phenotypes. Am J Med Genet 31: 533-548.

Mitchell JA, Packman S, Loughman WD, Fineman RM, Zackai E, Patil SR, Emanuel B, Bartley JA, Hanson JW. 1981. Deletions of different segments of the long arm of chromosome 4. Am J Med Genet 8:73-89.

Ockey CH, Feldman GV, Macaulay ME, Delaney MJ. 1967. A large deletion of the long arm of chromosome No. 4 in a child with limb abnormalities. Arch Dis Child 42:428-434.
Sebat J, Lakshmi B, Troge J, Alexander J, Young J, Lundin P, Månér S, Massa H, Walker M, Chi M, Navin N, Lucito R, Healy J, Hicks J, Ye K, Reiner A, Gilliam TC, Trask B, Patterson N, Zetterberg A, Wigler M. 2004. Largescale copy number polymorphism in the human genome. Science 305: 525-528.

Shen L, Li XF, Shen AD, Wang Q, Liu CX, Guo YJ, Song ZJ, Li ZZ. 2010. Transcription factor HAND2 mutations in sporadic Chinese patients with congenital heart disease. Chin Med J (Engl) 123:16231627.

Srivastava D, Thomas T, Lin Q, Kirby ML, Brown D, Olson EN. 1997. Regulation of cardiac mesodermal and neural crest development by the bHLH transcription factor, dHAND. Nature Genet 16:154160 .

Stanczak P, Witecka J, Szydlo A, Gutmajster E, Lisik M, Augusciak-Duma A, Tarnowski M, Czeka T, Czekaj H, Sieron AL. 2009. Mutations in mammalian tolloid-like 1 gene detected in adult patients with ASD. Eur J Med Genet 17:344-351.

Strehle EM, Ahmed OA, Hameed M, Russell A. 2001. The 4q-syndrome. Genet Couns 14:327-339.

Strehle EM, Bantock HM. 2003. The phenotype of patients with 4qsyndrome. Genet Couns 14:195-205.

Uppal S, Diggle CP, Carr IM, Fishwick CWG, Ahmed M, Ibrahim GH, Helliwell PS, Latos-Bielenska A, Phillips SEV, Markham AF, Bennett CP, Bonthron DT. 2008. Mutations in 15-hydroxyprostaglandin dehydrogenase cause primary hypertrophic osteoarthropathy. Nat Genet 40: 789-793. Note: Erratum: Nature Genet 40: 927.

Yamagishi H, Olson EN, Srivastava D. 2000. The basic helix-loop-helix transcription factor, dHAND, is required for vascular development. J Clin Invest 105:261-270.

Yu CW, Chen H, Baucum RW, Hand AM. 1981. Terminal deletion of the long arm of chromosome 4 . Report of a case of 46, XY, del(4)(q31) and review of 4q- syndrome. Ann Genet 24:158-161. 